\title{
THE BACKGROUND AND DEVELOPMENT OF QUALITY OF LIFE AND FAMILY QUALITY OF LIFE: APPLYING RESEARCH, POLICY, AND PRACTICE TO INDIVIDUAL AND FAMILY LIVING
}

\section{Roy I. Brown and Alice Schippers}

\begin{abstract}
This article introduces the concepts of quality of life and family quality of life and shows how they have developed in the field of intellectual and developmental disabilities in terms of concepts and principles. The article underscores the relevance of many of the principles and practices to a wide range of disabilities and challenges in the broad field of human development. Finally, the article provides an introduction to the other articles in this special issue, and considers their relationship to the broader areas of research, practice, and policy.
\end{abstract}

Keywords: quality of life, families, disabilities and other challenges, practice and policy development, research development

Acknowledgements: We are grateful to Dr. Sibylle Artz for encouraging us to prepare this special issue of the Journal. We would also like to acknowledge Ms. Susan Scott, the Associate Editor, for her invaluable contribution in copyediting. We are also grateful to Dr. Nancy Jokinen for her helpful suggestions. Several individuals were involved in reviewing the articles and we recognise the time and thought they gave to this important role. Finally we would like to thank the authors who have worked diligently and patiently in completing their contributions.

Roy I. Brown PhD (the corresponding author) is Adjunct Professor at the School of Child and Youth Care, University of Victoria, PO Box 1700, STN CSC, Victoria BC V8W 2Y2, Canada, and Emeritus Professor at the University of Calgary, Canada and Flinders University, Australia. Email: royibrown@shaw.ca

Alice Schippers $\mathrm{PhD}$ is a coordinating Senior Researcher at the Disability Studies Unit of the Medical Humanities Department of the Amsterdam University Medical Center, De Boelelaan 1089a, 1081 HV Amsterdam, The Netherlands. She is also the General Director of Disability Studies in the Netherlands. Email: alice.schippers@ disabilitystudies.nl 
In this foreword we introduce readers to some of the major characteristics of both individual and family quality of life as a background to the articles that follow. Quality of life ${ }^{1}$ (QOL) and family quality of life (FQOL) are relevant to all of us, and are particularly critical as we face challenges in our lives, whether as individuals or families. In this special issue we present research, practice, and personal experience from the field of intellectual and developmental disabilities (IDD) to indicate the potential application of QOL to a wide range of challenges in other areas of experience, and show how it may be valuable to individuals and families as well as professionals living and working in a variety of areas of need across the lifespan. We recognise that such an inductive approach can overreach its remit, so examples are provided to illustrate transfer to other life challenges in terms of both research and application.

Identifying the causes - and the means of resolution - of such challenges is relevant to a wide range of families, and needs to be considered by professional and family supporters, whether working in the field of intellectual and developmental disabilities, brain injury, or mental health, or confronting the critical crises that can arise with any individual or family. Such challenges frequently go beyond the family and have repercussions in the wider community and in society as a whole. The degree and kind of support may differ in these situations but the paradigm of QOL in the field of intellectual and developmental disability seems to have much to offer to other areas of individual and family concern (Brown \& Faragher, 2018).

The notion of QOL has a long past: its origins go back at least to Aristotle. The term then used was eudaimonia, which relates to satisfaction of an individual's needs (see Parmenter, 2018; Schippers, 2010). The topic, as a formal social and psychological concept, was introduced by Thorndike in the 1930s but not addressed in detail in the field of intellectual and developmental disabilities until the early 1980s. Research and practice have since expanded, first in terms of individual QOL, and then in the early 21st century in terms of FQOL (Turnbull, Brown, \& Turnbull, 2004).

\section{Definitions and Development in IDD}

A number of formal definitions of QOL and FQOL have been offered (see Brown \& Brown, 2003). At a generic level the definitions encompass the social well-being enjoyed by people, communities, and their society. QOL and FQOL are optimised when a person's basic needs are met and when he or she has the opportunity - or the family has the opportunity - to pursue and achieve goals in major life settings. Such goals might include experiencing certain types of education or employment, or becoming involved in certain types of sporting activities.

\footnotetext{
${ }^{1}$ Quality of life has also been referred to as well-being.
} 
International Journal of Child, Youth and Family Studies (2018) 9(4): 1-11

Satisfactory FQOL also requires that the family has opportunities to pursue, achieve, and enjoy life even when challenges are present. For example, it is neither unusual nor satisfactory to find that where there is severe disability, parents may not be able to go out together or take vacations. The FQOL literature is replete with examples of this type (Turnbull et al., 2004; Kober, 2010; Brown, Geider, Primrose, \& Jokinen, 2011; I. Brown, 2016).

These concerns are expressed around the world and exemplified by Keith and Schalock (2000) in Cross-Cultural Perspectives of Quality of Life. Nor are the concerns limited to particular people or specific fields of endeavour as can be seen in the detailed accounts of research and practice in Romney, Brown, and Fry (1994), which included issues of well-being in the field of mental health. The latter theme was further developed by Renwick, Brown, and Nagler (1996) whose book has chapters on QOL in relation to HIV, sexual abuse, homelessness, and aging, as well as IDD. A further and more comprehensive overview of QOL can be read in the Encyclopedia of Quality of Life and Well-Being Research (Michalos, 2014).

Both the QOL and FQOL approaches have specific and general implications such as the importance of the well-being of individuals and families, the need for ways of assessing wellbeing, and the development of methods to address challenges and needs as they become known. The resulting studies have significance for the design and development of government policies and the means by which support and intervention can take place.

Since the 1980s, QOL has become an increasing concern in the field of IDD. This field includes conditions such as Down syndrome, cerebral palsy, autism spectrum disorder, and a vast range of other genetic and environmental impacts including early birth injuries and accidents in a child's developmental years. The research of Goode (1994) and Brown, Bayer, and Brown (1992) gives detailed accounts of QOL intervention in this field, while a book edited by Brown (1997) provides a broader canvas, including a chapter on indigenous people in Canada. Later, Schalock et al.'s (2002) overview of this work in the field of IDD helped to shape the development of theory, research, and practice, leading to a set of principles that are relevant to research, service, and policy development.

The range of international QOL research has been increasing. For example, in the last few years, studies have been done in Italy (Lombardi, Croce, Claes, Vandervelde \& Schalock, 2016), Slovenia (Schmidt, Schmidt, \& I. Brown, 2017), and Israel (Roth \& I. Brown, 2017), as well as in Asian countries (e.g., Krishnasamy, Li, \& Chen, 2016).

\section{Principles of QOL}

The principles of QOL have been expanded and clarified, and most recently set into a broad pattern that covers QOL and FQOL across the lifespan. We briefly introduce these important QOL principles here as they constitute a practical paradigm that is relevant as a 
International Journal of Child, Youth and Family Studies (2018) 9(4): 1-11

background to the articles in this special issue (see Brown, Cobigo, \& Taylor, 2015 for further details).

First there are general principles. These include items such as dignity of people with disability, ethically based policy and practice, personal and professional values, the duty of care, managing risk and safety, the principle of normalisation, and attending to concerns that arise in terms of exclusion and inclusion. Although these overarching principles apply in the field of IDD, they also have relevance to other areas in which a wide range of professionals and informed laypersons deliver service, comfort, and support to their fellow human beings. It is now recognised that it is very important that people with disabilities should have life opportunities like everybody else in the community, opportunites that can assist development and learning and lead to improvement in overall QOL.

The most major challenge in QOL research and practice - apart from assessment, support, and education - is probably to encourage communities in all countries to become more involved and more supportive in terms of people's rights and respect for individuals regardless of the disabilities or limitations they may have. Exclusion and discrimination become dominant when there is an imbalance of power - when society imposes decisions on marginalised people (Schippers, Bakker, \& Peters, 2018; Baur \& Abma, 2011). Their freedoms and their opportunities for learning must be considered when support is provided; this requires working to ensure that their experiences of daily living are what the individual or family concerned regard as desirable.

The second set of principles of QOL relate to specific aspects of development and learning and can be divided into those concerning the individual, and those concerning the environment.

The individual: These principles include accepting that QOL is affected by the resilience of the person, their perceptions, their self-image, the degree of empowerment that is available to them and can be encouraged in and developed by them, and the extent of their personal control over situations and activities. In this context there needs to be recognition of the intrapersonal and interpersonal variability that occurs amongst individuals and families. One might ask, for example, how familiarity and unfamiliarity impact the various principles outlined, such as perception and self-image. We know that an unfamiliar environment as well as conditions of new learning can frequently reduce behavioural performance even to the level of impairing a person's language and motor behaviour (Hutt, Hutt, \& Ounsted, 1963; Brown \& Semple, 1970).

The environment: These principles concern the wide range of life domains that every individual experiences. They relate to education, family life, financial security, links with the community, type and level of employment, and ability to live effectively both in the family and in the communities with which each person is associated. All of these areas are important for individuals. They are also critical for families, and particularly family carers. 
International Journal of Child, Youth and Family Studies (2018) 9(4): 1-11

Another aspect of environment is holism. That is, all components of QOL are linked together, for each affects the others. Health impacts both physical activity and psychological state, but physical activity and psychological state also influence health. How the QOL components are managed together requires a re-examination not only of the services provided in each of the life domains but also of the links between them; moreover, comprehensive and supportive multidisciplinary teams must be developed, along with opportunities for engaging with the domains. This fundamentally affects how families operate, how communities respond to individuals, and what facilities are required in areas such as employment and leisure.

\section{Putting Principles and Areas Together}

Imagining and planning for the future is important for people with challenges and disabilities as well as for their families and their support services. Such imagining needs to take into account all the areas itemised above. For example, predicting the impact of an increasingly aging population and imagining their needs is critical for countries and agencies if they are to provide the necessary services and avert complex challenges where the resources to meet the requirements are not available. A good example of this is the fact that in many developed countries certain types of surgical operation (e.g., hip replacements) are often delayed, not only causing pain but also impacting psychological and physical well-being.

From the above, we see that the principles of QOL apply not just to children and young adults but to everyone across their lifespan. The variables involved, including the types of supports and the types of interventions that are required, will differ both by amount and level throughout life. For example, many people with IDD may be included in comprehensive education; however, in many countries, when they come to the end of the school cycle they are frequently sent to agencies that provide workshop-like activities segregated from the general community, where they do not get adequate payment.

Finally, a critical issue affecting QOL is the availability of opportunities for the individual to make choices. People require access to a wide range of opportunities, and they should be supported and able to express their choices. Indeed, to teach using people's own choices is much more likely to influence behaviour in a positive direction (Brown et al., 1992). In other words, individuals need support when they make choices, but they also require understanding and, depending on the nature of the challenges, adequate time to absorb information and to build this into their learned repertoire. All the above principles and ideas are relevant not just to the individual who has IDD but to a wide range of individuals who face challenges in everyday life.

\section{The Articles - Rationale and Relevance}

One of the challenges facing qualitative research that applies to many of the articles in this special issue is an embedded notion in some areas of science that the results from such research are subjective and not objective. Both Dehaene (2014) and Patton (2015) have 
International Journal of Child, Youth and Family Studies (2018) 9(4): 1-11

challenged this view and Brown (2017) provided arguments and examples to illustrate that such data when appropriately recorded are objective. It is the interpretation of the results that is often subjective. In the articles that follow precautions have been taken to check reliability and validity.

The sequence of articles in this special issue is strongly influenced by our view that without a detailed knowledge of the issues faced by individuals and families the development of policy is likely to be faulty.

We begin with a research-based article to give a clear overview of QOL measurement and structure in the general population. The article by Bob Cummins covers large samples of various general populations and goes on to describe the levels of satisfaction in relation to economic and social status. He puts forward a theoretical framework to indicate how QOL can be viewed as a homeostatic process that at times may temporarily shift as the result of variations occurring in an individual's life. He argues that a person's basic outlook or satisfaction is related to inheritance but can be modified by life experiences.

In the next article Kierstyn Butler examines one of the tools for assessing FQOL. She describes the background to the Family Quality of Life Survey and provides examples of the types of answers one obtains from families and the relevance to individual as well as to overall family need. Such information is important for the future development of services. She also provides information for using the survey for clinical applications as well as in research.

The following two articles are by members of the same family, Margaret and Nicole Kyrkou, a mother and daughter who are professionals in the field of disabilities and who themselves have a family member with severe disabilities. The articles look at a range of challenges for the person with disability and the day-to-day challenges for other family members. These represent areas that professionals and others involved with such families need to be aware of so they will be able to take appropriate action.

The article by Meaghan Edwards et al. examines ways in which our understanding of family needs can be supported in terms of improving individual social conditions through applied psychological and social actions.

In a study of multicultural families in the Netherlands, Femke Boelsma and colleagues examine the social experiences, situations, and needs of parents and their children in their communities. Recognising the importance of validating interview statements, the researchers constructed a detailed analysis of the data involving independent assessment by several skilled assessors. The results indicated a wide range of views underscoring how the norms and values of society influence the types and levels of support that vulnerable families receive. The authors emphasise the needs of the family members regardless of where they are living: their need to feel their family is accepted by society, and to feel that others perceive them as being full members of the local community. 
International Journal of Child, Youth and Family Studies (2018) 9(4): 1-11

Hanna Peels and Sofie Sergeant take on an important challenge for individuals who have limited oral communication. The authors have developed an interesting way of tapping into the interests and life experiences of people who face difficulties in interacting with those around them. The authors are exploring imagery through verbal narrative and metaphor and individuals' drawings as a basis for interaction. Their careful application of qualitative methodology is used to increase the range of discussion involving their clients and to cross-validate the findings that emerge. Such an approach has interesting possibilities and is suited to deal with an issue raised by Brown (2017) and discussed earlier in this article: that qualitative data are fundamentally objective not subjective. Information obtained from indivduals and recorded is factual. The challenge is to provide rational and valid interpretations of the hard data collected. It is the interpretation that is in danger of being subjective.

The next two articles, one by Belaynesh Tefera et al. and the other by Sue Wilson demonstrate how the QOL/FQOL paradigm and its principles can be applied within very different situations that present a variety of challenges, and that arise under very different circumstances.

Tefera and colleagues examine the plight of families in Ethiopia and describe major social and psychological stresses for families and children, particularly those with physical disabilities. The article provides examples of the importance of insight and the relevance of changing existing values if people and policy in all countries are to respect and support individuals with such needs. This is an example of the types of change envisaged by writers such as Parmenter (2018) and Turnbull (2018).

The following article, by Wilson, uses the QOL conceptual framework and its principles to examine the challenges related to anxiety and self-image that preservice teachers face in learning aspects of mathematics teaching, and the potential negative effects on the performance of the students they will eventually teach.

The final article, by Bob Schalock et al., concerns policy; it underscores many of the comments and recommendations in the previous articles. The development of policy in a systematic manner is critically important, yet policy also has to be developed from the experiences of individuals with disabilities and other challenges, and their families and other primary carers, along with professionals who have intimate knowledge of the families concerned. Such a need is also reflected in an article by Schippers, Zuna, and Brown (2015) in which they provided an integrated framework of policy and practice at the individual and the family levels, with positive QOL outcomes as the ultimate aim of professional support and policy making.

\section{Concluding Comments}

In this special issue we have included several articles that explore newer approaches to validating and interpreting research involving qualitative methodologies. This is critical because 
results from qualitative research are often accorded less weight due to the strong influence of a traditionl positivist approach that views qualitative data as subjective. We need to take seriously the scientifically recorded experiences and views of individuals with life challenges and their family members, and of practitioners if we are to see changes in policy and support.

The majority of these articles are based on cooperative research or written by authors with lived experience themselves within their family. With regard to FQOL and QOL, the experiences of those who live with disability on a daily basis are critical to our understanding of individual challenges and disabilities. First, as content, their direct experience adds to the relevance of research projects and practice; second, the process of attempting to understand those experiences leads to new and creative methods of exploration, trust, and commitment amongst those involved. When people with disabilities and other challenges are actively involved as equal partners in both research and practice it adds to their self esteem and feeling of belonging, and thus to their QOL (Frankena, Naaldenberg, Cardol, Linehan, \& van Schrojenstein Lantman-de Valk, 2015; Schippers et al., 2018).

Experience in the community is important, as are the resulting perceptions of both family members and the community. The articles underscore the arguments of authors such as Turnbull and colleagues (2004) and Parmenter (2018) who have stressed the relevance of personal and societal values and the importance of helping society to better understand and become involved in the support of vulnerable individuals and their families. Determining how best to work with society to change values and perceptions remains a major need and challenge in the 21 st century. 
International Journal of Child, Youth and Family Studies (2018) 9(4): 1-11

\section{References}

Baur, V. E., \& Abma, T. A. (2011). Resident councils between lifeworld and system: Is there room for communicative action? Journal of Aging Studies, 25(4), 390-396. doi:10.1016/j.jaging.2011.03.001

Brown, I. (2016). Family quality of life: A comparison of trends in eight countries. In V. P. Prasher (Ed.), Contemporay issues in intellectual disabilities (pp. 255-264). New York, NY: Nova.

Brown, I., \& Brown, R. I. (2003). Quality of life and disability: An approach for community practitioners. London, UK: Jessica Kingsley.

Brown, R. I. (Ed). (1997). Quality of life for people with disabilities - Models, research and practice. Cheltenham, UK: Stanley Thornes.

Brown, R. I. (2017). Quality of life — Challenges to research, practice and policy. Journal of Policy and Practice in Intellectual Disabilities, 14(1), 7-14. doi:10.1111/jppi.12185

Brown, R. I., Cobigo, V., \& Taylor, W. D. (2015). Quality of life and social inclusion across the lifespan: Challenges and recommendations. International Journal of Developmental Disabilities, 61, 93-100. doi:10.1179/2047386914Z.00000000092

Brown, R. I., Bayer, M. B., \& Brown, P. M. (1992). Empowerment and developmental handicaps: Choices and quality of life. Toronto, ON: Captus.

Brown, R. I., \& Faragher, R. M. (Eds.). (2018). Quality of life and intellectual disability: Knowledge application to other social and educational challenges (Softcover ed.). NewYork, NY: Nova Science.

Brown, R. 1., Geider, S., Primrose, A., \& Jokinen, N. S. (2011). Family life and the impact of previous and present residential and day care support for children with major cognitive and behavioural challenges: A dilemma for services and policy. Journal of Intellectual Disability Research, 55(9), 904-916. doi:10.1111/j.1365-2788.2011.01453.x

Brown, R. I., \& Semple, L. (1970). Effects of unfamiliarity on the overt verbalization and perceptual motor behaviour of nursery school children. British Journal of Educational Psychology, 40(3), 291-298. doi:10.1111/j.2044-8279.1970.tb02134.x

Dehaene, S. (2014). Consciousness and the brain: Deciphering how the brain codes our thoughts. New York, NY: Penguin. 
International Journal of Child, Youth and Family Studies (2018) 9(4): 1-11

Frankena, T. K., Naaldenberg, J., Cardol, M., Linehan, C., \& van Schrojenstein Lantman-de Valk, H. (2015). Active involvement of people with intellectual disabilities in health research: A structured literature review. Research in Developmental Disabilities, 45, 271283. doi:10.1016/j.ridd.2015.08.004

Goode, D. A. (Ed.). (1994). Quality of life for persons with disabilities: International perspectives and issues. Cambridge, MA: Brookline.

Hutt, C., Hutt, S. J., \& Ounsted, C. (1963). A method for the study of children's behavior. Developmental Medicine \& Child Neurology, 5(3), 233-245.

Keith, D. K., \& Schalock, R. L. (2000). Cross-cultural perspectives of quality of life. Washington, DC: American Association on Mental Retardation.

Kober, R. (Ed.). (2010). Enhancing the quality of life of people with intellectual disabilities: From theory to practice. Dordrecht, The Netherlands: Springer.

Krishnasamy, M., Li, J.-Y., \& Chen., D.-T. (2016). Transition outcomes through the lens of quality of life: Proposing a consolidated framework. Journal of Intellectual \& Developmental Disability. 41(4), 360-369. doi:10.3109/13668250.2016.1217983

Lombardi, M., Croce, L., Claes, C., Vandevelde, S., \& Schalock, R. (2016). Factors predicting quality of life for people with intellectual disability: Results from the ANFFAS study in Italy. Journal Of Intellectual \& Developmental Disability, 41(4), 338-347. doi:10.3109/13668250.2016.1223281

Michalos, A. C. (Ed.). (2014). Encyclopedia of quality of life and well-being research. Dordrecht, The Netherlands: Springer.

Parmenter, T. R. (2018). Inclusion and quality of life: Are we there yet? In R. I. Brown \& R. M. Faragher (Eds.), Quality of life and intellectual disability: Knowledge application to other social and educational challenges (Softcover ed., pp. 299-318). New York, NY: Nova Science.

Patton, M. Q. (2015). Qualitative research \& evaluation methods (4th ed.). Los Angeles, CA: Sage.

Renwick, R., Brown, I., \& Nagler, M. (Eds.). (1996). Quality of life in health promotion and rehabilitation: Conceptual approaches, issues, and application. Thousand Oaks, CA: Sage.

Romney, D. M., Brown, R. I., \& Fry, P. S. (Eds.). (1994). Improving the quality of life: Recommendations for people with and without disabilities. Dordrecht, The Netherlands: Kluwer. 
International Journal of Child, Youth and Family Studies (2018) 9(4): 1-11

Roth, D., \& Brown, I. (2017). Social and cultural considerations in family quality of life: Jewish and Arab Israeli families' child-raising experiences. Journal of Policy and Practice in Intellectual Disabilities, 14, 68-77. doi:10.1111/jppi.12208

Schalock, R. L., Brown, I., Brown, R. I., Cummins, R A., Felce, D., Matika, L., ... Parmenter, T. (2002). Conceptualization, measurement and application of quality of life for persons with intellectual disabilities : Report of an international panel of experts. Mental Retardation. 40(6), 457-470. doi:10.1352/0047-6765(2002)040<0457:CMAAOQ>2.0.CO;2

Schippers, A. (2010). Quality of life in disability studies. Medische Antropologie: Tijdschrift over gezondheid en cultuur [Medical Anthropology: A journal about health and culture], 22(2), 277-288.

Schippers, A., Bakker, M., \& Peters, L. (2018). Van participatie naar sociale inclusie [From participation to social inclusion] (with summary in English). Nederlands Tijdschrift voor de Zorg aan mensen met verstandelijke beperkingen [Dutch Journal for the Support of People with Intellectual Disabilities], 44(2), 106-118.

Schippers, A., Zuna, N., \& Brown, I. (2015). A proposed framework for an integrated process of improving quality of life. Journal of Policy and Practice in Intellectual Disabilities, 12, 151-161. doi:10.1111/jppi.12111

Schmidt, J., Schmidt, M., \& Brown, I. (2017). Quality of life among families of children with intellectual disabilities: A Slovene study. Journal of Policy and Practice in Intellectual Disabilities, 14, 87-102. doi:10.1111/jppi.12188

Turnbull, H. R. (2018). Four under-considered intersections. In R. I. Brown \& R. M. Faragher (Eds.), Quality of life and intellectual disability: Knowledge application to other social and educational challenges (Softcover ed., pp. 287-298). New York, NY: Nova Science.

Turnbull, A., Brown, I., \& Turnbull, H. R., III (Eds.). (2004). Families and people with mental retardation and quality of life: International perspectives. Washington, DC: American Association on Intellectual and Developmental Disabilities. 